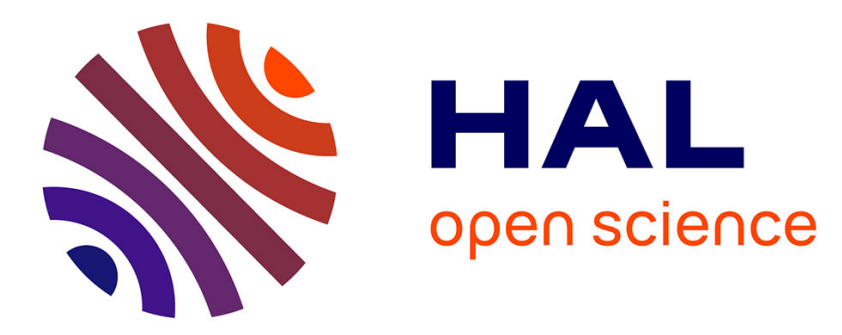

\title{
Three peanut-allergic/sensitized phenotypes with gender difference
}

\author{
Jocelyne Just, C. F. Elegbede, A. Deschildre, J. Bousquet, A. \\ Moneret-Vautrin, A. Crepet
}

\section{- To cite this version:}

Jocelyne Just, C. F. Elegbede, A. Deschildre, J. Bousquet, A. Moneret-Vautrin, et al.. Three peanutallergic/sensitized phenotypes with gender difference. Clinical and Experimental Allergy, 2016, 46 (12), pp.1596-1604. 10.1111/cea.12791 . hal-01377021

\section{HAL Id: hal-01377021 \\ https://hal.sorbonne-universite.fr/hal-01377021}

Submitted on 6 Oct 2016

HAL is a multi-disciplinary open access archive for the deposit and dissemination of scientific research documents, whether they are published or not. The documents may come from teaching and research institutions in France or abroad, or from public or private research centers.
L'archive ouverte pluridisciplinaire HAL, est destinée au dépôt et à la diffusion de documents scientifiques de niveau recherche, publiés ou non, émanant des établissements d'enseignement et de recherche français ou étrangers, des laboratoires publics ou privés. 


\section{Three peanut allergic/sensitized phenotypes with gender difference}

\section{7 words}

\section{Short title: peanut allergic/sensitized phenotypes}

4 Jocelyne JUST MD PhD ${ }^{1}$, Chabi Fabrice ELEGBEDE PhD ${ }^{2,3}$, Antoine DESCHILDRE MD ${ }^{4}$,

5 Jean BOUSQUET MD $\mathrm{PhD}^{5}$, Denise Anne MONERET-VAUTRIN MD $\mathrm{PhD}^{6}$, Amélie

6 CREPET $\mathrm{PhD}^{2}$ and the Mirabel study group

$7{ }^{1}$ Allergology Department, Centre de l'Asthme et des Allergies. Hôpital d'Enfants Armand-

8 Trousseau - 26, Avenue du Dr. Arnold Netter, 75571 PARIS Cedex 12 - INSERM, UMR_S

9 1136, Sorbonne Universités, UPMC Univ Paris 06 - Institut Pierre Louis d'Epidémiologie et

10 de Santé Publique, Equipe EPAR, F-75013, Paris, France

$11{ }^{2}$ Risk Assessment Department (DER), French Agency for Food, Environmental and 12 Occupational Health Safety (ANSES), Maisons-Alfort, France

$13{ }^{3}$ French National Institute for Agricultural Research (INRA), Paris Institute of Technology 14 for Life, Food and Environmental Sciences (AgroParisTech), UMR Economie Publique 15 INRA-AgroParisTech, France

$16{ }^{4}$ Pneumologie et allergologie pédiatriques, pôle enfant, hôpital Jeanne de Flandre, University 17 Hospital, Université Lille Nord de France, 59037 Lille cedex, France

185 CHRU de Montpellier, 34295 Montpellier cedex 5, France. Electronic address: 19 jean.bousquet@orange.fr.

$20{ }^{6}$ Allergyvigilance Network, Vandoeuvre les Nancy, France - Lorraine University, Nancy 21 France 


\section{Pr. Jocelyne JUST}

24 Centre de l'Asthme et des Allergies. Hôpital d'Enfants Armand-Trousseau (APHP) - 26,

25 Avenue du Dr. Arnold Netter, 75571 PARIS Cedex 12. France.

Tel. +33144736317

Fax: +33144736635

E-mail: jocelyne.just@trs.aphp.fr

Acknowledgment of funding: this work was funded by the French Research Agency (ANR) under reference ANR-10-ALIA-2012.

\section{Contributors}

Jocelyne JUST: involvement in the conception, hypotheses delineation, writing the article and substantial involvement in its revision prior to submission

34 Chabi Fabrice ELEGBEDE: acquisition, analysis and interpretation of the data, and substantial involvement in its revision prior to submission Antoine DESCHILDRE: involvement in the conception, hypotheses delineation, acquisition, analysis and interpretation of the data, and substantial involvement in its revision prior to submission

Denise Anne MONERET-VAUTRIN: involvement in the conception, hypotheses delineation, acquisition, analysis and interpretation of the data, and substantial involvement in its revision prior to submission Jean BOUSQUET: interpretation of the data, and substantial involvement in its revision prior to submission 
44 Amélie CREPET: involvement in the conception, hypotheses delineation, acquisition, 45 analysis and interpretation of the data, writing the statistical analysis part of the article and 46 substantial involvement in its revision prior to submission

47

48 Acknowledgments

49 This work was funded by the French Research Agency (ANR) under reference ANR-1050 ALIA-012-01. 


\section{Abstract 293 (300)}

Background: Peanut allergic reactions are heterogeneous ranging from mild symptoms to anaphylaxis. Objective: Identify peanut allergic/sensitized phenotypes to personalize patient management. Methods: A combined factor and cluster analysis was used to study the phenotypes of 696 patients diagnosed with peanut sensitization and enrolled in the MIRABEL survey. The method was first applied to the 247 patients with an Oral Food Challenge (OFC). It was then applied to the 449 patients without OFC to confirm the findings in an independent population. Results: Three independent clusters emerged from the OFC subgroup. Cluster 1, "Severe peanut allergy with little allergic multimorbidity" (123 subjects), had the highest proportion of patients with positive OFC (92\%), a medium level of peanut protein inducing a positive OFC (235 mg), lower percentage of allergic multimorbidity ( $2 \%$ asthma plus atopic dermatitis ( $\mathrm{A}+\mathrm{AD})$, no cases of $\mathrm{A}+\mathrm{AD}+$ multiple food allergies (MFA)). Cluster 2, "Severe peanut allergy with frequent allergic multimorbidity" (62 subjects), had a high proportion of patients with positive OFC $(85 \%)$ with the lowest level of peanut protein inducing a positive OFC (112mg), $89 \%$ allergic subjects, $100 \%$ with allergic multimorbidity (A+AD) and $84 \%$ with A+AD+MFA. Cluster 3, "Mild peanut allergic/sensitized phenotype" (62 subjects), had the lowest mean age, the lowest proportion of patients with positive OFC (53\%) with a high level of peanut protein inducing a positive OFC $(770 \mathrm{mg})$, a low percentage of allergic multimorbidity (48\% A+AD+MFA). The two severe peanut allergy phenotypes were more frequent in girls. The same clusters were found in the subgroup of patients without OFC. Conclusion \& Clinical Relevance: Besides the classic markers associated with lower threshold doses of OFC (such as SPT and rAra h2), allergic multimorbidity and female gender should also be taken into account to better adapt the progressive dosage of provocation tests. 
75 Key words: asthma, atopic dermatitis, cluster analysis, gender, peanut allergy,

76 multimorbidity.

\section{$77 \quad$ Abbreviations}

78 Specific immunoglobulin E: sIgE

79 Skin prick test: SPT

80 Atopic dermatitis: AD

81 Asthma: A

82 Allergic rhinitis: AR

83 Multiple Food Allergies: MFA

84 Oral food challenge: OFC

85 Number of words: 3573 (5000) 


\section{Introduction}

87 Peanut allergy is a common food allergy affecting up to $1.3 \%$ of children in Europe ${ }^{1}$. Its prevalence is on the increase and this is reflected in an increased prevalence of hospitalization for peanut-induced anaphylaxis in the United States ${ }^{2}$. However, the severity of systemic allergic reactions to peanut is variable and fatal peanut-induced anaphylaxis is rare $^{3}$. Moreover, a considerable number of children with positive specific immunoglobulin E (sIgE) and positive skin prick test (SPT) are asymptomatic or present a milder clinical picture ${ }^{4,5,6,7}$. Thus, it is crucial to better detect patients with a severe food allergy phenotype for appropriate follow-up care and management.

The diagnosis of peanut allergy in comparison to peanut sensitization is not always easy. The most relevant features to diagnose peanut allergy would appear to be clinical in real life or in provocation tests. Moreover, a small proportion of children with peanut allergy can outgrow their allergy ${ }^{8}$. On the other hand, the severity of the disease can also increase over time. This is illustrated by contradictory results in studies, some of which have previously suggested a relationship between a history of anaphylaxis or severe symptoms and the risk of anaphylaxis upon subsequent exposure and others the opposite $e^{9,10,11}$.

Nicolaou et al. ${ }^{12}$ found a high rate of false-positive SPT and irrelevant sIgE results for peanut. The threshold level of peanut sIgE or SPT to predict a positive provocation test is unclear ${ }^{1314}$. These discrepancies in the current approach to peanut allergy testing could be improved by component-resolved diagnosis which has been extensively explored in this area. In 2004, Koppelman et al. ${ }^{15}$ first suggested the importance of the peanut component rAra $\mathrm{h} 2$ in predicting reactivity or tolerance to peanut. More recently, other components of peanut such as rAra $\mathrm{h} 6$, have been found to be associated with the risk of anaphylaxis ${ }^{16}$. However, to date, a provocation test remains necessary not only to confirm diagnosis but also to assess the severity of peanut allergy (related to the threshold reactive dose). 
111 These features underline the necessity to perform provocation tests to distinguish between

112 peanut sensitized and allergic patients, but this test is at risk of anaphylaxis and time

113 consuming.

114 A novel approach to distinguish patients who present peanut allergic or sensitized phenotypes

115 with different clinical and biological characteristics, is to identify different disease phenotypes

116 by cluster analysis. This statistical approach has never been performed to identify

117 allergic/sensitized phenotypes.

118 The MIRABEL survey is a multicentre survey based on the voluntary participation of peanut119 allergic/sensitized patients from Metropolitan France, Belgium and Luxembourg to evaluate 120 the allergic risk in patients with well-characterized peanut allergy or sensitization ${ }^{17}$. It is thus 121 an ideal cohort in which to test the hypothesis that peanut allergic/sensitized phenotypes exist.

122 We set out to define allergic/sensitized phenotypes by unsupervised analysis in a subgroup of 123 patients of the MIRABEL survey who had undergone oral food challenges (OFC) taking into 124 account informative parameters such as clinical symptoms, SPT, sIgE to native and 125 informative epitopes ( $\mathrm{rAra} h 2$ ). To generalize these phenotypes to the entire allergic 126 population, the same analysis was performed in an independent population of patients without 127 OFC. 


\section{MIRABEL design and inclusion of patients}

130 Between April 2012 and December 2013, allergists were asked to include consecutive 131 patients with suspected peanut allergy. Patients were then classified as "sensitized" on the 132 basis of positive SPT performed with commercial extracts (mean wheal diameter $\geq 3 \mathrm{~mm}$ ) and 133 sIgE to rAra h $2(\geq 0.35 \mathrm{kUA} / \mathrm{L} \text {; ImmunoCAP, Thermofisher, Sweden })^{18}$ without any clinical 134 reaction, or "allergic" based on sensitization (as previously defined) with an allergic reaction 135 to peanut exposure.

\section{Ethics}

137 The study was approved by the French Data Protection Authority (CNIL) (Authorization no. 138 DE-2011-048). All patients or parents signed an informed consent.

\section{Medical questionnaire and oral food challenge}

140 Data were collected by a questionnaire filled in by the allergist after medical diagnosis of 141 peanut allergy and included the following variables (as previously published ${ }^{19}$ ). Briefly:

142 The age at diagnosis of peanut allergy.

143 Symptom severity during real-life exposure was classified into two categories: mild to 144 moderate reactions (urticaria or angioedema without respiratory symptoms, rash/dermatitis, 145 isolated and mild to moderate gastro intestinal symptoms); or severe reactions (anaphylactic 146 shock, laryngeal angioedema, acute asthma, systemic serious reaction (involving two or more 147 organs $)^{20}$. 
149 Active allergic comorbidities over the past year, including asthma (A), atopic dermatitis (AD),

150 allergic rhinitis (AR) and multiple food allergies (MFA) were diagnosed by an experienced

151 allergist from the patient's medical records.

152 SPT were performed using different peanut and food extracts (mainly from Stallergènes,

153 Antony, France). As the MIRABEL survey is observational, the patients were administered

154 the OFC according to the physician's practice either by a single-blind or double-blind

155 placebo-controlled challenge or as an open OFC. For positive OFCs, the reactive cumulated

156 dose, based on objective symptoms only, was expressed in mg of peanut protein equivalent.

157 The OFC was considered negative in the absence of an objective sign for a cumulative dose $\geq$

$1587 \mathrm{~g}$ of peanut.

159 Dietary advice provided by the allergist was recorded as: "strict eviction" if the patient was

160 advised to avoid all products containing peanuts and products with PAL; compared with a

161 combined category of "lax" if the patient was merely advised to avoid products containing 162 peanuts but that PAL products were allowed; and "absent" if the patient was advised that no 163 avoidance was necessary.

\section{$164 \quad$ Variable selection for cluster analysis}

165 The variables for statistical analysis were those that reflected physiologic parameters (age at 166 diagnosis and age at time of OFC, gender) and those related to the clinical presentation of 167 peanut allergy such as the allergic/sensitized status, route of exposure that induced reaction 168 (ingestion and/or inhalation and/or contact), the test results (SPT, $\mathrm{rAra} \mathrm{h}$ 2, OFC) and allergic 169 comorbidities. In case of two highly correlated variables, only the one considered as the most relevant was retained in the analysis. The variables selected for analysis are marked in Table 1 
171 by $a^{\ddagger}$. Composite variables were used to distinguish patients with one, two or three

172 multimorbidity symptoms: one variable for patients with both A and AD (A+AD), and one for 173 patients with both $\mathrm{A}+\mathrm{AD}$ and MFA (A+AD+MFA).

\section{$174 \quad$ Variable reduction and cluster analysis}

175 Phenotype clusters were identified by coupling a factor analysis with a cluster analysis as 176 previously reported by Just et al.$^{19}$. A factor analysis for mixed data (categorical and 177 continuous) was first applied to the selected variables to study their associations and identify 178 which variables contributed the most to explaining the variability of the dataset ${ }^{21}$. Factor 179 analysis also makes it possible to reduce the dimension of the dataset to a few principal 180 components. A hierarchical cluster analysis was then applied to these principal components to 181 classify the population into homogeneous groups of peanut allergy severity. The method is 182 based on Ward's minimum variance criterion which minimizes the total within-cluster 183 variance. The distance between individuals was calculated using the Euclidian distance. Thus, 184 variables between the different groups were compared using the one-way ANOVA test for 185 continuous variables and the Chi-squared test for categorical variables. The Kruskal-Wallis 186 and the Fisher's exact tests were respectively used when the required conditions were not 187 respected to perform the ANOVA and the Chi-squared tests. Statistical analyses were 188 performed with the FactoMineR package of $\mathrm{R}$ version 3.1.1. 
189

190

191

193

194

195

196

197

198

199

200

201

202

203

204

\section{Results}

\section{Description of the population}

785 patients were recruited by 70 allergists. Complete information was available for 696 patients, and 247 of these had complete OFC results. The variables have been fully described in a previous article about the MIRABEL survey ${ }^{17}$.

\section{Variable associations}

Factor analysis applied to the OFC subgroup using all selected variables resulted in three principal components explaining $46 \%$ of the total variance. The first component was composed of allergic multimorbidity variables. The second component was composed of the age at which the OFC was conducted and the time between diagnosis and the OFC. The third component included SPT, sIgE to rAra h 2 and OFC results. A similar structure was obtained when applying factor analysis to the population without OFC, except that the allergic/sensitized status was also part of the second component and associated with age at diagnosis.

\section{Peanut allergic/sensitized phenotypes of the 247 patients with $\mathrm{OFC}$}

Three independent clusters emerged from the application of a hierarchical classification on the three principal components selected from the previous factor analysis.

Cluster 1, "Severe peanut allergy with little allergic multimorbidity" (123 subjects), had the highest proportion of patients with positive OFC (92\%), the highest proportion of severe reactions upon exposure via ingestion (84\%), a medium level of peanut protein equivalent inducing a positive OFC (235 mg) associated with a high mean level of rAra h $2(34 \mathrm{kUA} / \mathrm{l})$, and finally a lower percentage of allergic multimorbidity (2\% asthma plus atopic dermatitis $(\mathrm{A}+\mathrm{AD})$, no cases of $\mathrm{A}+\mathrm{AD}+\mathrm{MFA}) \quad($ Table 1$)$.

Cluster 2, "Severe peanut allergy with frequent allergic multimorbidity" (62 subjects), had a 
213 high proportion of patients with positive OFC (85\%) with the lowest level of peanut protein

214 inducing a positive OFC (112mg) associated with the highest mean level of SPT wheal size

$215(13 \mathrm{~mm})$, the highest mean level of rAra h $2(43 \mathrm{kUA} / \mathrm{l})$ and the highest proportion of severe

216 reactions upon exposure via inhalation. This cluster was characterized by the highest

217 percentage of allergic multimorbidity compared to the two other clusters, $100 \%$ (A+AD) and

218 84\% A+AD+MFA (Table 1).

219 Cluster 3, "Mild peanut allergic/sensitized phenotype" (62 subjects), had the lowest mean 220 disease duration (3.5 years), the lowest proportion of patients with positive OFC (53\%) with

221 the highest level of peanut protein inducing a positive OFC (770 $\mathrm{mg})$, a low percentage of 222 allergic multimorbidity (48\% A+AD+MFA) and AD only found in a high percentage of cases $223(95 \%)($ Table 1).

224 Peanut allergic/sensitized phenotypes in subgroup of patients without OFC

225 Clusters of the subgroup without OFC $(n=449)$ are similar to those of the OFC subgroup 226 ( $\mathrm{n}=247)$, for most parameters and especially for allergic comorbidities (Table 2). The results 227 were consistent even though the statistical significance of some variables decreased slightly.

\section{Analysis based on gender}

229 Separate cluster analyses were carried out for boys and girls with OFC. These analyses 230 identified the same three clusters as the previous analysis for the boys (Table 3) but only two 231 clusters for the girls (Table 4) i.e. the severe peanut allergic phenotypes called the "Severe 232 peanut allergy with frequent allergic multimorbidity" and the "Severe peanut allergy with 233 little allergic multimorbidity”. 
236 Cluster analysis of the MIRABEL data showed that peanut allergy is a heterogeneous disease.

237 The clustering approach divided the population into two subgroups of severe peanut 238 phenotypes "Severe peanut allergy with little allergic multimorbidity" and "Severe peanut 239 allergy with frequent allergic multimorbidity" and one non-severe subgroup "Mild peanut 240 allergic/sensitized phenotype”. The severe peanut allergy phenotypes were more frequently 241 encountered in girls.

\section{$242 \quad$ Strengths and weaknesses}

243 One strength of this study is that it is a multicenter study performed in large population of 696 244 peanut allergic/sensitized patients recruited by allergists. Moreover, for a large part of this 245 population (almost 250), peanut allergy was diagnosed by OFC, although the reasons for 246 undergoing an OFC or not are not known in this real-life survey. Another strength is that the 247 statistical analyses to identify different phenotypes were conducted by an unsupervised 248 approach with a large range of variables and in a large cohort of patients with severe allergy.

249 The factor analysis was conducted in several steps. A first analysis was performed including 250 all available variables; a second analysis was then conducted excluding variables that were 251 too highly correlated, variables that did not play a large role in explaining the variance, and in 252 combining some variables frequently encountered in patients with multiple food 253 allergies/sensitization. The phenotypes described here remain stable in all the analyses. 254 Moreover, this concordance of three phenotypes (established in patients with and without 255 OFC) highlights the one message of our article, i.e. the importance of multiple comorbidities 256 (especially $\mathrm{A}+\mathrm{AD}$ or $\mathrm{A}+\mathrm{AD}+\mathrm{MFA}$ ) to define a particular phenotype of severe peanut-allergy. 257 One limitation of the study is the different ways in which the OFC was carried out. However, 258 this actually reflects physicians' daily practices and the OFCs selected for analysis were supported by objective symptoms (for positive OFC) and a high dosage of peanut ingested 
260 during OFC (> $7 \mathrm{~g}$ of peanut) for the negative test. Similarly, SPTs were not standardized.

261 Another limitation of our study is the heterogeneity of the population, in which patients were 262 probably at different disease stage (for instance, initial diagnosis vs. resolution of peanut

263 allergy). This explains cluster 3 which has the lowest mean disease duration (3.5 years) with 264 the highest proportion of sensitized children. This result is in accordance with the natural 265 history of the disease in which sensitization (more than allergy) is associated with a smaller 266 diameter of the SPT and lower levels of rAra h $2^{8}$. The clustering algorithms are different 267 when working on the group with OFC and the group without. We consequently analyzed the 268 group with OFC as follows: first using the variables related to the OFC (as presented), and 269 then without the variables related to OFC. Three similar phenotypes were obtained with both 270 methods (data not shown). Therefore, we can conclude that we do not need to have 271 information about OFC to correctly classify a patient into the right cluster. Finally, by our 272 analysis, it was not possible to distinguish at individual level, sensitized or allergic patient, 273 but parameters associated to severe allergic phenotypes (in our cluster analysis) will be taking 274 into account to adapt the schedule of provocation tests.

\section{"Severe peanut allergy with frequent allergic multimorbidity"}

277 This result underlines that allergic multimorbidity (asthma with AD and/or MFA) is 278 associated with a higher reported severity of peanut-induced allergic reactions. Colver et al. 279 showed that asthma was a strongly significant risk factor for severe allergic reactions to food, specifically with peanut ${ }^{22}$. Bock et al. reported similar findings among 32 fatal cases; all of

281 those for whom medical records were available had a history of asthma ${ }^{23}$. Summers et al. ${ }^{24}$, in 282 a study of 1,094 patients with tree nut and peanut allergies demonstrated that, as well as 283 severe asthma being associated with life-threatening bronchospasm, severe pharyngeal edema 284 was more common in patients with severe AR. They also found that having severe AD was 
associated with a 3-fold increased risk of becoming unconscious during an acute allergic reaction, thus further highlighting the link between the severity of acute allergic reactions and the severity of co-existing atopic disease. We recently described ${ }^{25}$, a "Multiple Allergies and Severe Asthma phenotype" in which $100 \%$ of the children had AD and multiple sensitizations. This is very close to the "Severe peanut allergy with frequent allergic multimorbidity" phenotype we present here. This phenotype could correspond to the previously described 291 phenotype of AD associated with filaggrin loss-of-function mutations associated to a greater risk of severe asthma ${ }^{26}$.

"Severe peanut allergy with little allergic multimorbidity" or the high proportion of patients with severe reaction during OFC had a high level of rAra $h 2$

295 This severe phenotype underlines the axis of recombinant rAra $\mathrm{h} 2$ in predicting clinical severity of peanut allergy. rAra h 2 is a heat-stable seed-storage protein and is considered to 297 be the major peanut allergen contributing to peanut sensitization. Peeters et al. looked at 298 whether sensitization to rAra h $1,2,3$, or 6 can predict the severity of allergic reactions to peanut in a group of 30 patients. They found that patients with severe reactions had a greater SPT response to rAra h 2 and rAra h 6 at low concentrations and to rAra h 1 and rAra h 3 at 301 higher concentrations. They also found that patients with more severe symptoms recognized a 302 greater number of allergens. Sensitization to rAra h 2 plus sensitization to rAra h 1 and/or 303 rAra h 3 was associated with greater severity of reactions ${ }^{27}$. Peptide microarray 304 immunoassays in a group of 77 patients similarly showed that those with wide epitope 305 diversity were associated with a history of more severe allergic reactions ${ }^{28}$. 
308 The subjects in this phenotype were younger at diagnosis, more likely to be sensitized

309 (41.9\%), had the lowest positive allergic reaction during OFC, the smallest SPT wheal size,

310 the lowest mean levels of rAra h 2 and a higher percentage of AD (95\% of cases). This

311 phenotype could correspond to the current hypothesis that allergic sensitization to food occurs

312 through low-dose cutaneous sensitization ${ }^{29}$. Many studies suggest ${ }^{30,31,32}$ that late introduction

313 of potential food allergens and cutaneous exposure ${ }^{33}$ might be associated with allergy while

314 early oral exposure might contribute to tolerance. It is thus possible that the young children in 315 our mild peanut phenotype could be in the process of developing real peanut allergy in the 316 case of delayed oral exposure.

\section{More females have the severe phenotypes of peanut allergy: a possible gender effect}

318 The food allergy register has already shown an age-dependent gender distribution, with a M/F 319 sex ratio of 0.67 from early adulthood, in contrast to children where the ratio is $1.50^{34}$. Similar 320 differences in gender have emerged from several questionnaire-based studies in other 321 countries $^{35,36}$. This observed age-related gender difference is similar to that reported for 322 asthma, hay fever and atopic disease, suggesting that puberty and the influence of sex 323 hormones may have an important impact on the prevalence of atopic diseases in general $^{37}$. In 324 the same vein, a survey reporting on severe allergic reactions defined by the necessity of 325 medical care, showed a higher incidence of food allergy in females. Finally, an Australian 326 study has also reported that females outnumbered males in both acute allergic reactions and 327 anaphylaxis ${ }^{38}$.

\section{Conclusions}

329 Our results underline that, beside the classic markers associated with lower threshold doses of 330 OFC (such as SPT or rAra h2), allergic multimorbidity and female gender should also be 331 taken into account to better adapt the progressive dosage of provocation tests. 


\section{Acknowledgments}

The authors wish to thank Sélina TSCHEILLER (analyst at the Allergy Vigilance Network) for her contribution to the analysis and all the allergists who participated in the MIRABEL survey: Dr ALT Roger, Strasbourg; BANOUN Laurence, Le Raincy ; BEAUMONT Pascale, Saint Maur des Fossés ; BEGON Isabelle, Paris ; BLANCHARD Paul, Desertines ; Boix Françoise, Angers ; BONNEFOY GUIONNET Bénédicte, Saint-Lo ; CHABANE Habib, Saint-Denis ; CHATEAU-WAQUET Dominique, Paris ; CORDEBAR Vanina, Thionville ; COUSIN Marie-Odile, Lille ; DE BLAY Fréderic, Strasbourg ; De Hauteclocque Cécile, Creil ; Delaval Yvonne, Rennes; DELEBARRE-SAUVAGE Christine, Lille ; DEVOISINS Jean Marc, Cholet ; DOYEN Virginie, Bruxelles ; DRON-GONZALVEZ Mireille, Martigues; DROUET Martine, Angers ; DUMOND Pascale, Nancy ; DUMOULIN Anne, Brest ; DZVIGA Charles, Saint Etienne ; EPSTEIN Madeleine, Paris ; FLABBEE JennyAnne, Thionville ; FONTAINE Monique, Reims ; FRENTZ Pascale, Thionville ; GAYRAUD Jacques, Tarbes ; GIBOURY LAFARGE Sophie, Verneuil sur Sein ; GRANET Patricia, Digne les Bains ; Guenard-Bilbaud Lydie, Strasbourg ; HALLET Jean-Louis, Luneville ; HATAHET Riad, Forbach ; Langlet Catherine, Bayonne ; Lepeltier - Canavan Laurence, Caen; LEPRINCE Françoise, Saint Quentin; LETELLIER Edouard, Paris; LIABEUF Valérie, Marseille ; MARCHANDIN Anne, Luisant ; MASSABIE-BOUCHAT Yann-Patrick, Marseille ; Mazé Marie-Héléne, Plaisir ; MENETREY Céline, Limoges ; MERCIER Valérie, Toulouse ; MONSIGNY Monique, Chauny ; MOREL-CODREANU Françoise, Luxembourg ; MOUTON FAIVRE Claudie, Nancy ; MULLIEZ-PETITPAS Julie, Poitiers ; NICOLAS Pascale, Poissy; OUTTAS Omar, Clermont-Ferrand; PASQUET- NOUALHAGUET Christine, Bois d'Arcy ; PEROTIN-COLLARD Jeanne-Marie, Reims ; PETIT Nicolas, Verdun ; PIRSON Francoise, Bruxelles ; POUVREAU Hélène, Poitiers ; PUILLANDRE Erick, Arcachon ; SABOURAUD-LECLERC Dominique, Reims ; SAINT MARTIN 
358 François, Villebon sur Yvette ; SANTOS Adjoke-Clarisse, Lille ; SERINGULIAN Alice,

359 Paris; SULLEROT Isabelle, Sens; TERRIER Patrick, Marmomme; THIERRY Marie-Hélène,

360 Alberville ; THIS-VAISSETTE Christine, Massy ; VIGAN Martine, Besançon; VODOFF

361 M.V, Mulhouse.

\section{Conflicts of interest}

363 A Deschildre reports personal consultancy and lecture fees from GSK, MSD, Aerocrine,

364 MEDA, ALK, Novartis, Stallergènes, Chiesi, outside the submitted work.

365 J Just reports reports personal consultancy and lecture fees from Novartis, ALK, Stallergènes,

366 Chiesi, phadia, Novartis, GSK, MSD, outside the submitted work.

367 E Beaudoin reports personal fees from ALK abello SA, MSD, Novartis, outside the submitted 368 work.

369 The rest of the authors declared that they have no relevant conflicts of interest. 
J JUST

370 


\section{References}

${ }^{1}$ Nwaru BI1, Hickstein L, Panesar SS, Roberts G, Muraro A, Sheikh A; EAACI Food Allergy and Anaphylaxis Guidelines Group. Prevalence of common food allergies in Europe: a systematic review and meta-analysis. Allergy 2014;69:992-1007.

${ }^{2}$ Lin RY, Anderson AS, Shah SN, Nurruzzaman F. Increasing anaphylaxis hospitalizations in the first 2 decades of life: New York State, 1990-2006. Ann Allergy Asthma Immunol 2008;101:387-93.

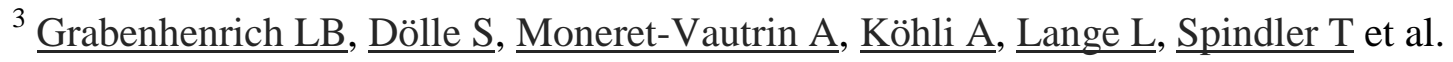
Anaphylaxis in children and adolescents: The European Anaphylaxis Registry. J Allergy Clin Immunol. 2016 ; S0091-6749(15)02991-7.

${ }^{4}$ Burks AW: Peanut allergy. Lancet 2008;371: 1538-46.

${ }^{5}$ Wood RA: The natural history of food allergy. Pediatrics 2003;111:1631-37.

${ }^{6}$ Patriarca G, Schiavino D, Pecora V, Lombardo C, Pollastrini E, Aruanno A et al. Food allergy and food intolerance. Intern Emerg Med 2009;4:11-24.

${ }^{7}$ Nicolaou N, Poorafshar M, Murray C, Simpson A, Winell H, Kerry G, et al. Allergy or tolerance in children sensitized to peanuts: prevalence and differentiation using componentresolved diagnostics. J Allergy Clin Immunol 2010;125: 191-7.

${ }^{8}$ Peters RL, Allen KJ, Dharmage SC, Koplin JJ, Dang T, Tilbrook KP et a. Natural history of peanut allergy and predictors of resolution in the first 4 years of life: A population-based assessment. J Allergy Clin Immunol 2015;135:1257-66.

${ }^{9}$ Summers CW1, Pumphrey RS, Woods CN, McDowell G, Pemberton PW, Arkwright PD. Factors predicting anaphylaxis to peanuts and tree nuts in patients referred to a specialist center. J Allergy Clin Immunol 2008;121:632-8.

${ }^{10}$ Calvani M, Cardinale F, Martelli A, Muraro A, Pucci N, Savino F et al. Italian Society of Pediatric Allergy and Immunology Anaphylaxis' Study Group. Risk factors for severe 
pediatric food anaphylaxis in Italy. Pediatr Allergy Immunol 2011;22:813-9.

${ }^{11}$ Yu JW, Kagan R, Verreault N, Nicolas N, Joseph L, St Pierre Y et al. Accidental ingestions in children with peanut allergy. J Allergy Clin Immunol 2006;118:466-72.

12 Nicolaou N1, Poorafshar M, Murray C, Simpson A, Winell H, Kerry G et al. Allergy or tolerance in children sensitized to peanut: prevalence and differentiation using componentresolved diagnostics. J Allergy Clin Immunol 2010;125:191-7.

${ }^{13}$ Nicolaou N, Custovic A. Molecular diagnosis of peanut and legume allergy. Curr Opin Allergy Clin Immunol 2011;11:222-8.

14 Dang TD, Tang M, Choo S, Licciardi PV, Koplin JJ, Martin PE et al. Increasing the accuracy of peanut allergy diagnosis by using Ara $h$ 2. J Allergy Clin Immunol 2012;129:1056-63.

${ }^{15}$ Koppelman SJ1, Wensing M, Ertmann M, Knulst AC, Knol EF. Relevance of Ara h1, Ara $\mathrm{h} 2$ and Ara h3 in peanut-allergic patients, as determined by immunoglobulin E Western blotting, basophil-histamine release and intracutaneous testing: Ara h2 is the most important peanut allergen. Clin Exp Allergy 2004;34:583-90.

${ }^{16}$ Otsu K, Guo R, Dreskin SC. Epitope analysis of Ara h 2 and Ara h 6: characteristic patterns of IgE-binding fingerprints among individuals with similar clinical histories. Clin Exp Allergy 2015;45:471-84.

${ }^{17}$ Crépet A, Papadopoulos A, Elegbede CF, Loynet C, Ait-Dahmane S, Millet G, et al. MIRABEL: an integrated framework for risk and cost/benefit analysis of peanut allergen. Regul Toxicol and Pharmacol 2015;71:178-83.

${ }^{18}$ Astier C, Morisset M, Roitel O, Codreanu F, Jacquenet S, Franck P,et al. Predictive value of skin prick tests using recombinant allergens for diagnosis of peanut allergy. J Allergy Clin Immunol. 2006;118:250-6. 
${ }^{19}$ Deschildre A, Elégbédé CF, Just J, Bruyère O, Van der Brempt X, Papadopoulos A et al. Peanut allergic patients in the MIRABEL survey: characteristics, allergists' dietary advice and lessons from real life. Clin Exp Allergy 2015 Nov 20.

${ }^{20}$ Ewan PW, Clark AT. Long-term prospective observational study of patients with peanut and nut allergy after participation in a management plan. Lancet 2001;357:111-5.

${ }^{21}$ Pagès J. Factorial Analysis of Mixed Data. In: Pagès J. Multiple Factor Analysis by Example Using R. Boca Raton: CRC Press, 2014; 67-78.

${ }^{22}$ Colver AF, Nevantaus H, Macdougall CF, Cant AJ. Severe food- allergic reactions in children across the UK and Ireland, 1998- 2000. Acta Paediatr 2005;94:689-95.

23 Bock SA, Muñoz-Furlong A, Sampson HA. Fatalities due to anaphylactic reactions to foods. J Allergy Clin Immunol 2001;107:191-3.

${ }^{24}$ Summers CW, Pumphrey RS, Woods CN, McDowell G, Pemberton PW, Arkwright PD. Factors predicting anaphylaxis to peanuts and tree nuts in patients referred to a specialist center. J Allergy Clin Immunol 2008;121:632-8.

25 Just J, Saint-Pierre P, Gouvis-Echraghi R, Laoudi Y, Roufai L, Momas I and al. Allergic Asthma Is Not a Single Phenotype. J Pediatr 2014;164:815-20.

${ }^{26}$ Marenholz I, Kerscher T, Bauerfeind A, Esparza-Gordillo J, Nickel R, Keil T, et al. An interaction between filaggrin mutations and early food sensitization improves the prediction of childhood asthma. J Allergy Clin Immunol 2009;123:911-6.

${ }^{27}$ Peeters KA, Koppelman SJ, van Hoffen E, van der Tas CW, den Hartog Jager CF, Penninks $\mathrm{AH}$ et al. Does skin prick test reactivity to purified allergens correlate with clinical severity of peanut allergy? Clin Exp Allergy 2007;37:108-15.

${ }^{28}$ Shreffler WG, Beyer K, Chu TH, Burks AW, Sampson HA. Microarray immunoassay: association of clinical history, in vitro IgE function, and heterogeneity of allergenic peanut epitopes. J Allergy Clin Immunol 2004;113:776-82. 
${ }^{29}$ Lack G. Epidemiologic risks for food allergy. J Allergy Clin Immunol 2008;121:1331-6.

${ }^{30}$ Fox AT, Sasieni P, du Toit G, Syed H, Lack G. Household peanut consumption as a risk factor for the development of peanut allergy. J Allergy Clin Immunol 2009;123:417-23.

31 Du Toit G, Katz Y, Sasieni P, Mesher D, Maleki SJ, Fisher HR, et al Early consumption of peanuts in infancy is associated with a low prevalence of peanut allergy. $\mathrm{J}$ Allergy Clin Immunol 2008;122:984-91.

${ }^{32}$ Nwaru BI, Erkkola M, Ahonen S, Kaila M, Haapala AM, Kronberg-Kippilä C et al. Age at the introduction of solid foods during the first year and allergic sensitization at age 5 years. Pediatrics 2010;125:50-9.

${ }^{33}$ Lack G, Fox D, Northstone K, Golding J. Factors associated with the development of peanut allergy in childhood. N Engl J Med 2003;348:977-85.

${ }^{34}$ Namork E1, Fæste CK, Stensby BA, Egaas E, Løvik M. Severe allergic reactions to food in Norway: a ten year survey of cases reported to the food allergy register. Int J Environ Res Public Health 2011;8:3144-55.

${ }^{35}$ Makinen-Kiljunen S, Haathela T. Eight years of severe allergic reactions in Finland; A register-based report WAO J 2008;1:184-9.

${ }^{36}$ Chen W, Mempel M, Schober W, Behrendt H, Ring J. Gender difference, sex hormones, and immediate type hypersensitivity reactions. Allergy 2008;63:1418-27.

${ }^{37}$ Uekert SJ, Akan G, Evans MD, Li Z, Roberg K, Tisler C et al. Sex-related differences in immune development and the expression of atopy in early childhood. J Allergy Clin Immunol 2006;118:1375-81.

${ }^{38}$ Brown AF, McKinnon D, Chu K. Emergency department anaphylaxis: A review of 142 patients in a single year. J Allergy Clin Immunol 2001;108:861-6. 